\title{
Technical Study of the Performance of Liquid Sulfur Combustion in the Process of Sulfuric Acid Production \\ ${ }^{1}$ Suwarmin, ${ }^{2}$ Bambang Sudarmanta, ${ }^{3}$ Nur Ikhwan* \\ $1,2,3$ Department of Mechanical Engineering, Institut Teknologi Sepuluh Nopember, Surabaya 60111, Indonesia \\ Received:4 January 2018, Revised: 1 March 2018, Accepted: 10 March 2018
}

\begin{abstract}
The production process of sulfuric acid is carried out in stages from combustion of liquid sulfur to $\mathrm{SO}_{2}$, then to $\mathrm{SO}_{3}$ and dissolving $\mathrm{SO}_{3}$ in aqueous sulfuric acid solution to concentrated sulfuric acid (high concentration). The success of the production process is very dependent on the initial combustion process into $\mathrm{SO}_{2}$, physical parameters on the liquid sulfur characteristics and the nozzle geometry. The process of burning liquid sulfur depends on the pattern of atomization in the geometry of the nozzle and its fluid characteristics. Liquid sulfur is included in non-newtonian fluids, so the atomization process requires an understanding of its characteristics. The atomization mechanism at the nozzle depends on 3 parameters including viscosity, surface tension and density. In non- Newtonian fluid 3 parameters are sensitive to changes in pressure and temperature. In terms of the geometry of the tip nozzle diameter, smaller diameter, the atomization process is better, but a decrease in temperature will cause clogging. Individual installation of temperature and pressure sensors for each nozzle is chosen so that the atomization of each nozzle can be controlled.
\end{abstract}

Keywords: Liquid sulfur, atomization, combustion, sulfuric acid and clogging

\section{Introduction}

Sulfuric acid $\left(\mathrm{H}_{2} \mathrm{SO}_{4}\right)$ is a corrosive liquid, colorless, odorless, highly reactive and capable of dissolving various metals. This chemical can dissolve with water at all comparisons, has a melting point of $10,31^{\circ} \mathrm{C}$ and boiling point at $336,85^{\circ} \mathrm{C}$ depending on density. And at a temperature of $300^{\circ} \mathrm{C}$ or more can decomposes to produce sulfur trioxide[1]. Sulfuric acid $\left(\mathrm{H}_{2} \mathrm{SO}_{4}\right)$ is one of the petrochemical industry products where the production process uses sulfur raw materials. In stoichiometry the process of sulfuric acid production is carried out by burning sulfur in stages then reacting with water.

Liquid sulfur which is clean from storage tanks is flowed into the underground sulfur burner feed pit and is equipped with a steam coil heater. This pit is also equipped with a vertical type sulfur pump, a burner feed pump where this pump pumps liquid sulfur into sulfur furnace with a pressure of about $10 \mathrm{~kg} / \mathrm{cm}^{2}$. Liquid sulfur entering the sulfur furnace is sprayed through sulfur burner and reacted with dry air from the drying tower to $\mathrm{SO}_{2}$ gas [2]. Subsequently the $\mathrm{SO}_{2}$ conversion becomes $\mathrm{SO}_{3}$ in a converter, that consists of four beds. Three beds are first level converters and the fourth bed is a second level converter. Each conversion rate has an absorber. Process gas containing $\mathrm{SO}_{2}$ gas with a temperature of $430^{\circ} \mathrm{C}$ enters the converter bed where about $60 \%$ of $\mathrm{SO}_{2}$ gas is converted to $\mathrm{SO}_{3}$ with $\mathrm{V}_{2} \mathrm{O}_{5}$ catalyst. Atmospheric air is sucked using an air blower through the drying tower. In this drying tower the water content in the air is absorbed by $\mathrm{H}_{2} \mathrm{SO}_{4}$ and produces dry air. Sulfuric acid $98.5 \%$ is circulated through drying tower. Dry air from a $109^{\circ} \mathrm{C}$ temperature air blower is fed into sulfur furnace as combustion air for sulfur oxidation. Gas containing $\mathrm{SO}_{3}$ from the last bed of the converter is absorbed by $98.5 \% \mathrm{H}_{2} \mathrm{SO}_{4}$ which is circulated in the absorbing tower to produce sulfuric acid[2].

In fact, the sulfuric acid industry will involve several parameters that will affect the reaction perfectly. Parameters include physical and chemical conditions. Physical parameters are both temperature, pressure and geometry, while the chemical parameters are catalysts included in the process. Conditioning physical parameters and the use of the right catalyst greatly affect the quantity and quality of production. The production process of sulfuric acid includes burning sulfur to $\mathrm{SO}_{2}, \mathrm{SO}_{2}$ to $\mathrm{SO}_{3}$ and dissolving $\mathrm{SO}_{3}$ to dilute sulfuric acid. In this process, not all $\mathrm{SO}_{2}$ becomes $\mathrm{SO}_{3}$, some come out through the stack. The quantity of $\mathrm{SO}_{2}$ coming out in free air is controlled according to environmental standards. The process of burning liquid material depends on several parameters. One of the most dominant parameters is the surface area that is in contact with air. In its implementation, increasing surface area and opportunity intersect with air through atomization mechanisms. Atomization using a nozzle aims to make the particles or droplets as small as possible and spread as large as possible. The size of the droplet and the distribution of the material to be burned are strongly influenced

\footnotetext{
*Email:suwarmin@me.its.ac.id, sudarmanta@me.its.ac.id, Ikhwan@me.its.ac.id
} 
by several parameters both the nozzle geometry, the physical properties of the liquid material and the operation. Combustion of liquid sulfur as the initial process of making sulfuric acid is a determinant of product quality and environmental effects. The atomization process is related to the 3 geometry of the nozzle and the physical properties of liquid sulfur need to be understood because it greatly influences the success of the combustion process.

The process of atomizing liquid spray is influenced by two main factors, namely internal factors such as physical properties of liquid (viscosity, density and surface tension) and external factors such as injection system geometry, operating conditions and airflow conditions. The effect is expressed in three parameters without dimensions, in the form of Reynolds number (Re), Weber number (We) and Ohnesorge number (Oh). Deformation is meaningful starting from We $=1$ which is a critical point. If We $>1$ makes the deformation break (break up) because the bond strength between fluid molecules can no longer resist the pressure that can break the fluid flow. In general, spray characteristics are expressed in average droplet size, droplet break-up, angle, speed and spray penetration [3] [4] [5] [6].

\section{Literature Review}

Sulfuric acid $\left(\mathrm{H}_{2} \mathrm{SO}_{4}\right)$ can be made from sulfur (S), pyrite (FeS) and also some metal sulfid (CuS, $\mathrm{ZnS}, \mathrm{NiS}$ ). In general, sulfuric acid is produced with levels of $78 \%$ $-100 \%$ and various oleum concentrations. In generally, the stages of the contact process that occur are described as follows:

1. Melting solid sulfur in melt tanks

2. Purification of liquid sulfur by filtration

3. Air drying process

4. Burning liquid sulfur with dry air for produce sulfur dioxide $\left(\mathrm{SO}_{2}\right)$

5. The $\mathrm{SO}_{2}$ advanced oxidation reaction becomes $\mathrm{SO}_{3}$ in four bed converters using a $\mathrm{V}_{2} \mathrm{O}_{5}$ catalyst

\section{Gas Cooling}

7. Absorption of $\mathrm{SO}_{3}$ with sulfuric acid $93 \%-98.5 \%$

The reactions that occur are as follows [3]:

$$
\begin{gathered}
\mathrm{S}+\mathrm{O}_{2} \rightarrow \mathrm{SO}_{2}+31.148 \mathrm{kcal} \\
\mathrm{SO}_{2}+\frac{1}{2} \mathrm{O}_{2} \rightarrow \mathrm{SO}_{3}+70.960 k \mathrm{kcal} \\
\mathrm{SO}_{3}+\mathrm{H}_{2} \mathrm{O} \rightarrow \mathrm{H}_{2} \mathrm{SO}_{4}+23.490 \mathrm{kcal}
\end{gathered}
$$

- Reaction 1. Occurs in the combustion tank, where sulfur atomized and reacted with dry air.
- Reaction 2. Occurs in a converter or reactor with a catalyst $\mathrm{V}_{2} \mathrm{O}_{5}$

- Reaction 3. Occurs in diluent tanks, sulfur gas trioxide is absorbed with sulfuric acid (93\% -98.5\%)

\section{Methodology}

The study carried out included analytical Study of the gun nozzle atomization process and numerical modeling gun nozzle. The numerical modeling is based on the FLUENT code methodology based on the finite volume approach. Governing equations for continuity equations, momentum and chemical species for gases and droplet sprays, together with state equations are calculated for each mesh cell. The set of equations produced are then numerically resolved to obtain macro spray characteristics in the form of development, penetration, and spray dispersion angles and micro spray characteristics in the form of average droplet diameter (SMD) and droplet speed, as well as emission formation and formation.

1. NUMERICAL GRID. Numerical grids are imported from GAMBIT code.

2. INITIAL CONDITIONS. Species density, turbulent kinetic energy is assumed to be uniform at the start of the calculation.

3. NUMERICAL MODELS. Numerical Models used in research include spray, viscous, solver, linearization and phase discretion.

\section{Results and Discussion}

4.1. Technical Data and Operating Conditions

Information on technical data evaluated includes the operation pattern and geometry of the gun nozzle, in the operation of sulfur in liquid conditions at certain temperatures. Conditioning using steam around the nozzle pipe. The atomization process using a gun nozzle is operated at a certain pressure (Figure 1).

The number of nozzle gun has 6 pieces, where the initial operation using oil burner. The gun nozzle burner is operated after the temperature is fulfilled. From the physical characteristics of liquid sulfur freezing temperature of $121.7^{\circ} \mathrm{C}$, the minimum operating temperature is $130^{\circ} \mathrm{C}$.

Table 1. Gun nozzle operational data

\begin{tabular}{|c|c|}
\hline P: $10-14 \mathrm{Mpa}$ & $\rho: 1790 \mathrm{~kg} / \mathrm{m} 3$ \\
$\mathrm{Q}: 2,4 \mathrm{~m} 3 / \mathrm{h}$ & $\sigma: 0,0608 \mathrm{~N} / \mathrm{m}$ \\
T: $130-140^{\circ} \mathrm{C}$ & Tekanan Inlet \\
Td: $121,7^{\circ} \mathrm{C}$ & Sulphur $: 1-1,4 \mathrm{MPa}$ \\
$\mu: 8,5-9,3 \mathrm{cP}$ & Uap $: 0,4-0,6 \mathrm{MPa}$ \\
\hline
\end{tabular}



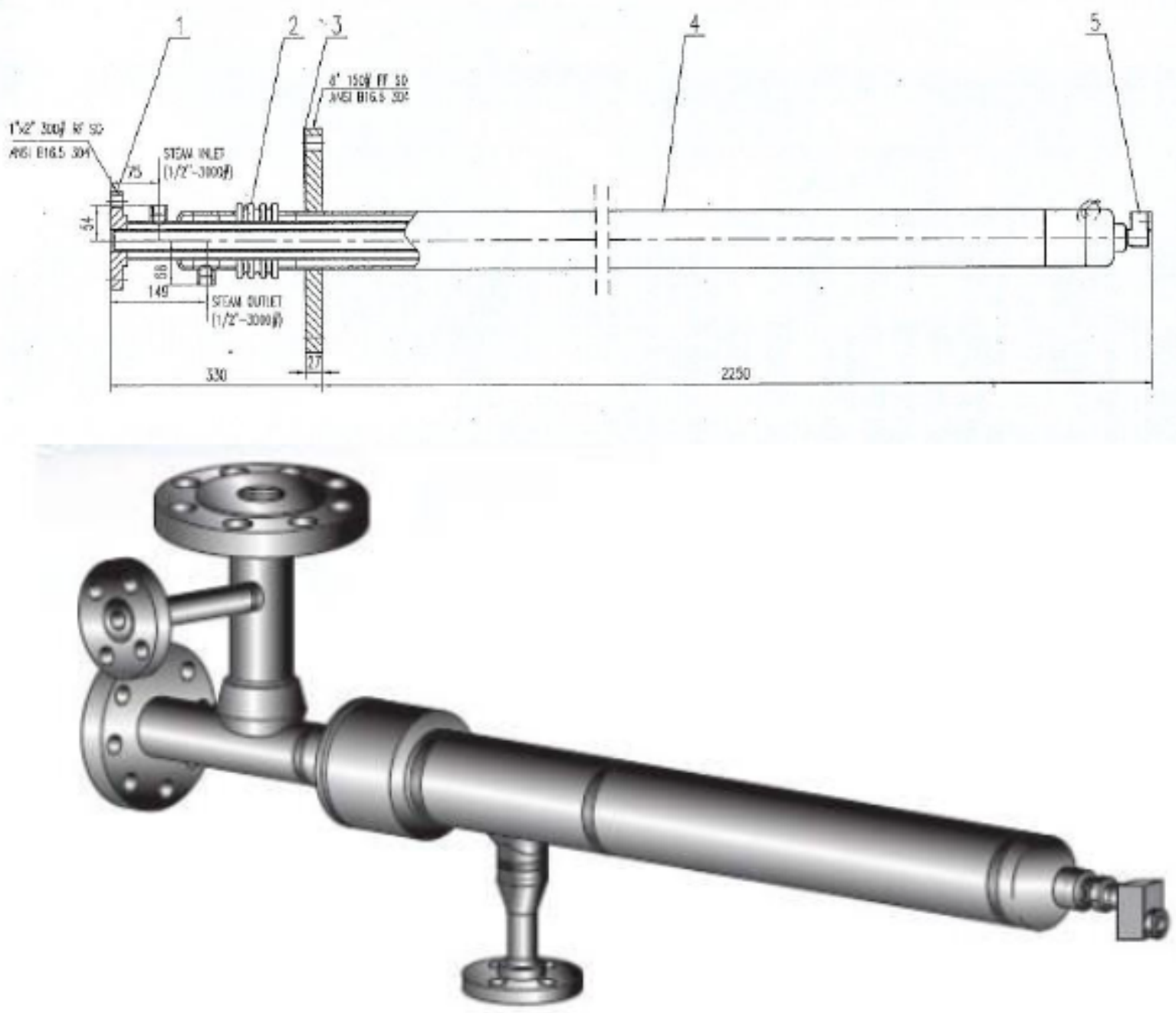

Figure 1. Assembly gun nozzle

The number of nozzle gun has 6 pieces, where the initial operation using oil burner. The gun nozzle burner is operated after the temperature is fulfilled. From the physical characteristics of liquid sulfur freezing temperature of $121.7^{\circ} \mathrm{C}$, the minimum operating temperature is $130^{\circ} \mathrm{C}$.

4.2. Analytical Study of the gun nozzle atomization process

The atomization process of the fluid at the gun nozzle aims to get a certain size of droplet diameter and spread. The process with criteria for droplets to ensure the process of burning sulfur to $\mathrm{SO}_{2}$ can take place perfectly.

\subsubsection{Characteristics of Liquid Sulfur}

Hot liquid sulfur which is atomized through the gun nozzle to be burned is a nonnewtonian fluid. The characteristics of the fluid are very specific where the viscosity and surface tension depend on temperature and pressure. In this case the temperature is very dominant. From the oper-
The parameters in the process of liquid sulfur atomization consist of the gun nozzle geometry and the nature or characteristics of liquid sulfur.

This geometry has the advantage of a hollow cone spray pattern and the trajectory in the nozzle is wide enough to avoid clogging or clumping.

\subsubsection{Geometry of Nozzle Gun}

The nozzle gun used includes the type of Hollow Cone Spray where whirl is formed from directly tangential speeds (Figure 2).

ational conditions the possibility of clogging / clumping will occur due to the temperature dropping or the distribution of the spread of heat from the steam unevenly. The atomization process starts from the flow of liquid sulfur with a pressure of $10 \mathrm{MPa}$ and temperature $130^{\circ} \mathrm{C}$ after passing through the nozzle it will be atomized in the form of droplets or granules of a certain size and amount. The 
chronological droplet formation process can be explained as follows.

The initial process comes out of the nozzle in ligament formation or lamellar where the fluid is sprayed in the form of a lamellar or sheet.

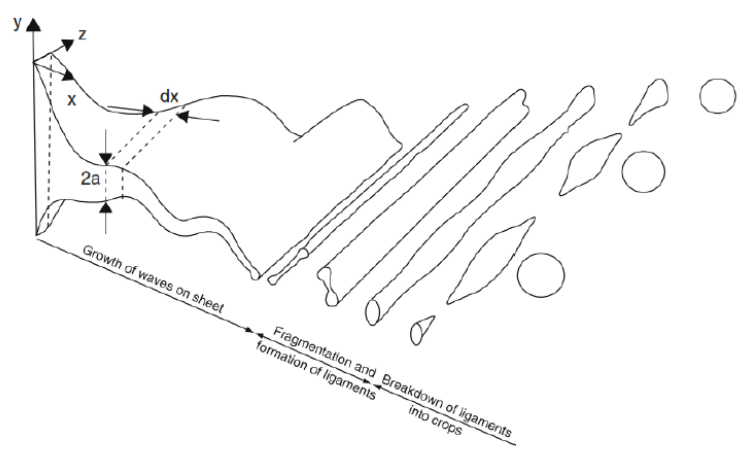

Figure 3. Formation of fluid ligaments at the nozzle

The second process after the ligament will form granules with large size. This form will initiate the atomization process into the desired droplet. This process will involve the physical parameters of the fluid in this case liquid sulfur. Some formulations from the Weber and Ohnesorge equations provide an indication of droplet formation based on viscosity, surface tension, density and spray speed.

- Weber number, We :

$$
W e=\frac{\rho_{1} U_{0}^{2} d_{0}}{\sigma}
$$

- Ohnesorge number, Oh :

$$
O h=\frac{\mu_{0}}{\sqrt{\rho_{d} \sigma d_{0}}}=\frac{\left[\left(\frac{\rho}{\rho_{g}}\right) W e\right]^{\frac{1}{2}}}{R e}
$$

The critical Ohnesorge number is 0.1 where above the initial grain it is difficult for the atomization process to be small. The dominant parameter in viscosity, from the operational side of this condition can be caused by a decrease in temperature. Oh (Ohnesorge) values below 0.1 atomization process are easier by controlling Weber numbers (Table ?? and Figure 4). The parameter varied is speed by keeping Oh values based on temperature.

The type of atomization process in operation in Bag Breakup, Multi mode breakup and Sheet-thinning breakup.

\subsubsection{Study of Numerical Models}

In principle, the Numerical Model study aims to determine the flow and pressure behavior of the gun nozzle. More detailed studies require measuring the real conditions of the operational conditions. In non-Newtonian fluids such as liquid sulfur the physical properties or characteristics change with temperature or pressure. Several other studies use physical models with the same fluid. In the case of liquid sulfur the challenge is the nature of the material that is toxic. Numerical modeling using 2 different types of tip nozzle with sizes $\oslash 11 \mathrm{~mm}$ and $\oslash 7 \mathrm{~mm}$.

At $7 \mathrm{~mm}$ tip nozlle diameter shows a higher speed range but with increasing viscosity it will decrease so that operational temperature conditions need to be maintained.
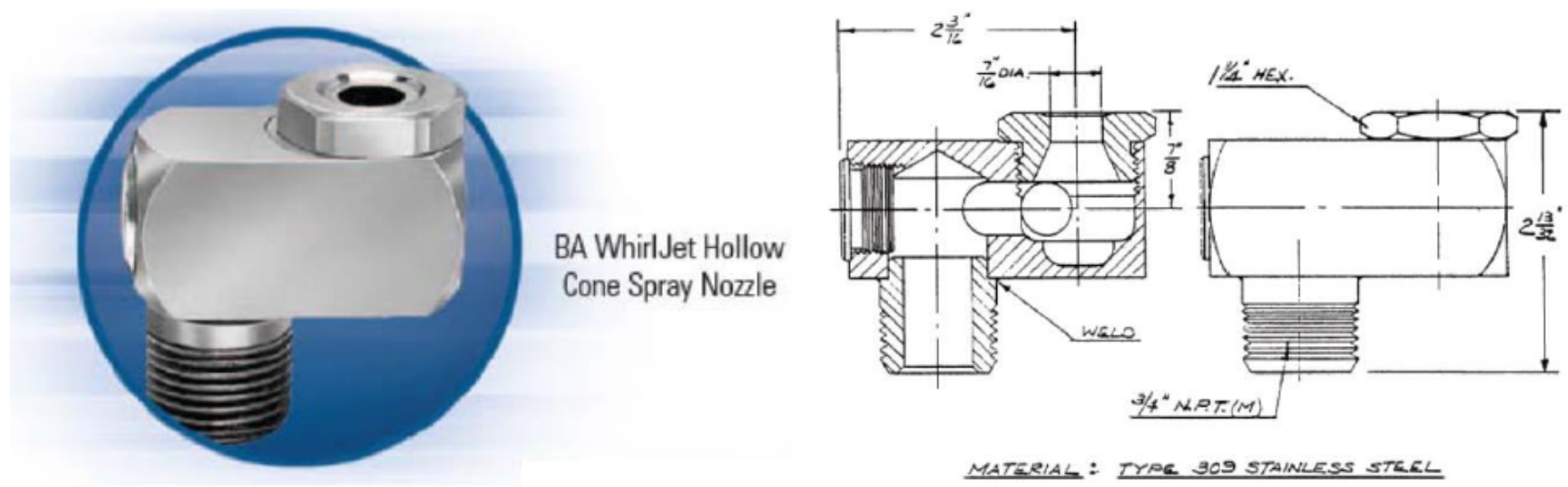

Figure 2. Geometry of Nozzle Gun 

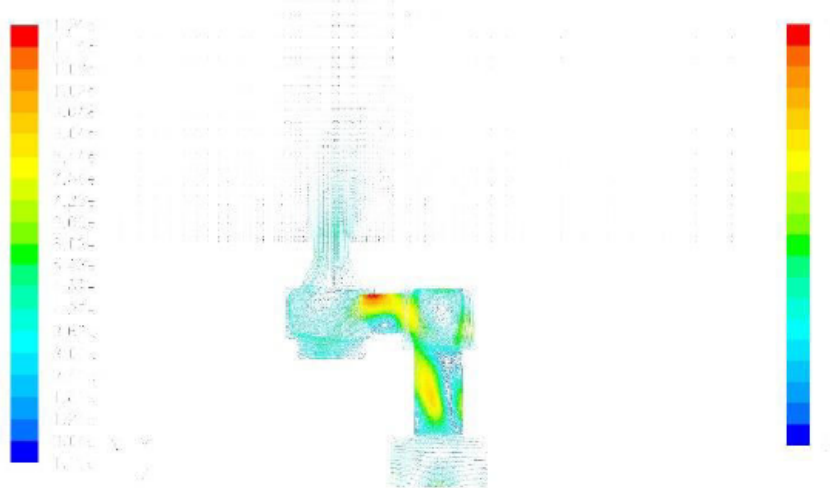

Figure 5. The velocity vector under conditions of viscosity of $8.5 \mathrm{cP}$ and $9.3 \mathrm{cP}$ and $\oslash$ tips $11 \mathrm{~mm}$
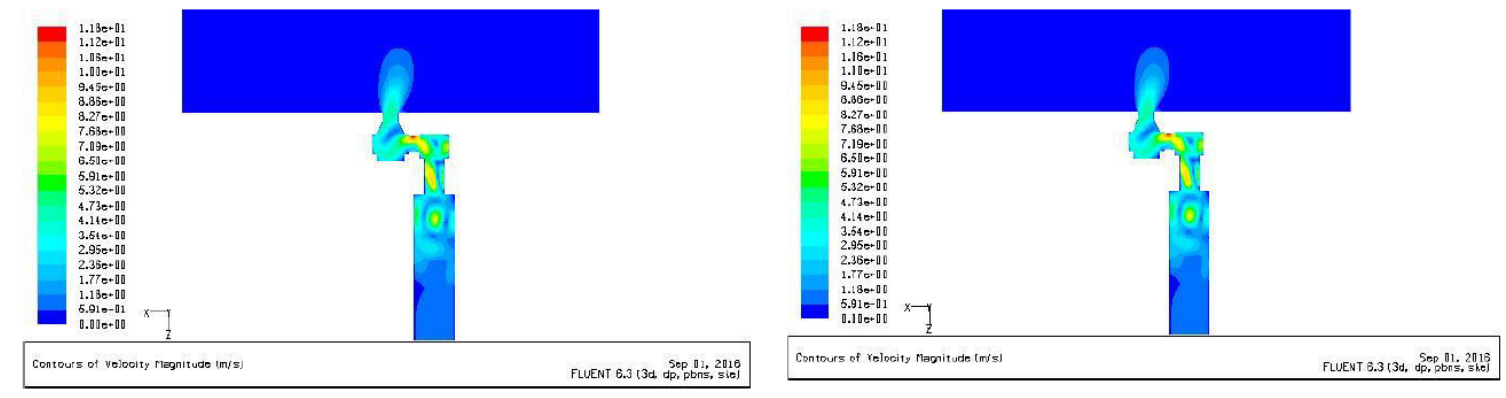

Figure 6. The velocity contour at a viscosity of $8.5 \mathrm{cP}$ and $9.3 \mathrm{cP}$ and $\oslash$ tips $11 \mathrm{~mm}$

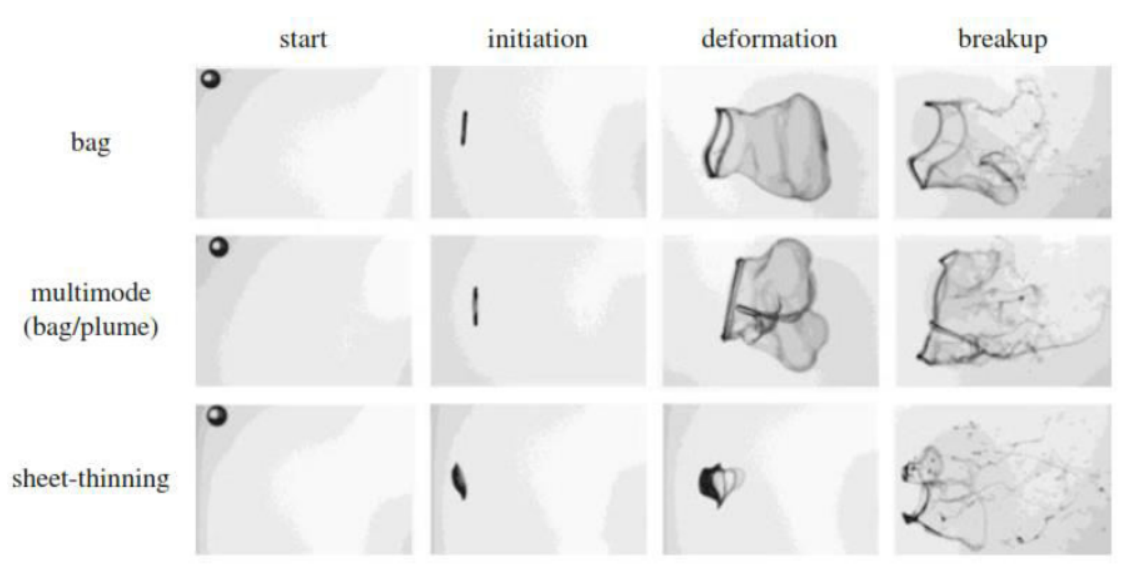

Figure 4. Non Newtonian fluid atomization process 


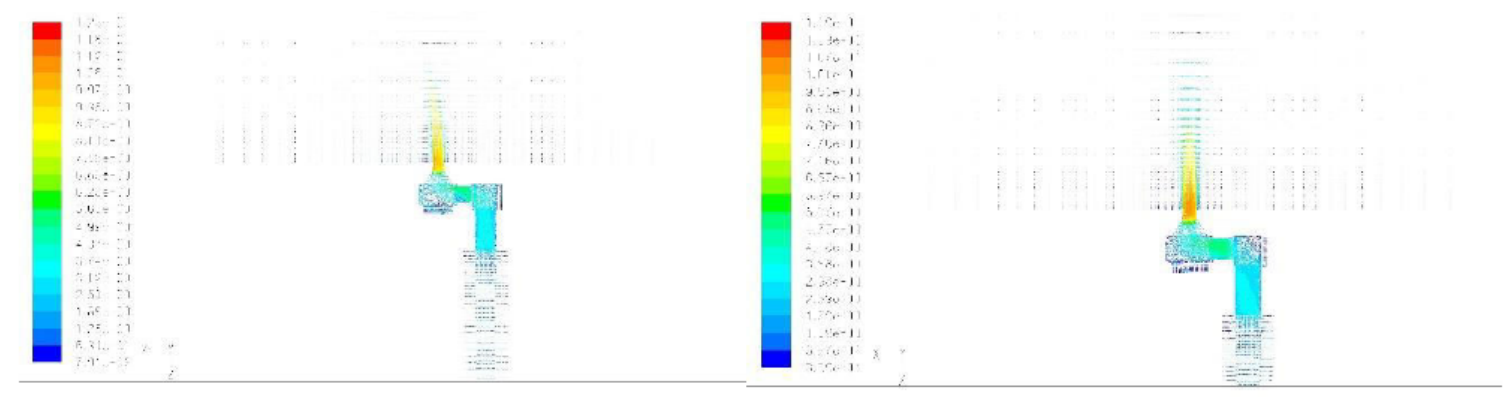

Figure 7. The velocity vector at $8.5 \mathrm{cP}$ viscosity and $9.3 \mathrm{cP}$ and $\oslash$ tips $7 \mathrm{~mm}$

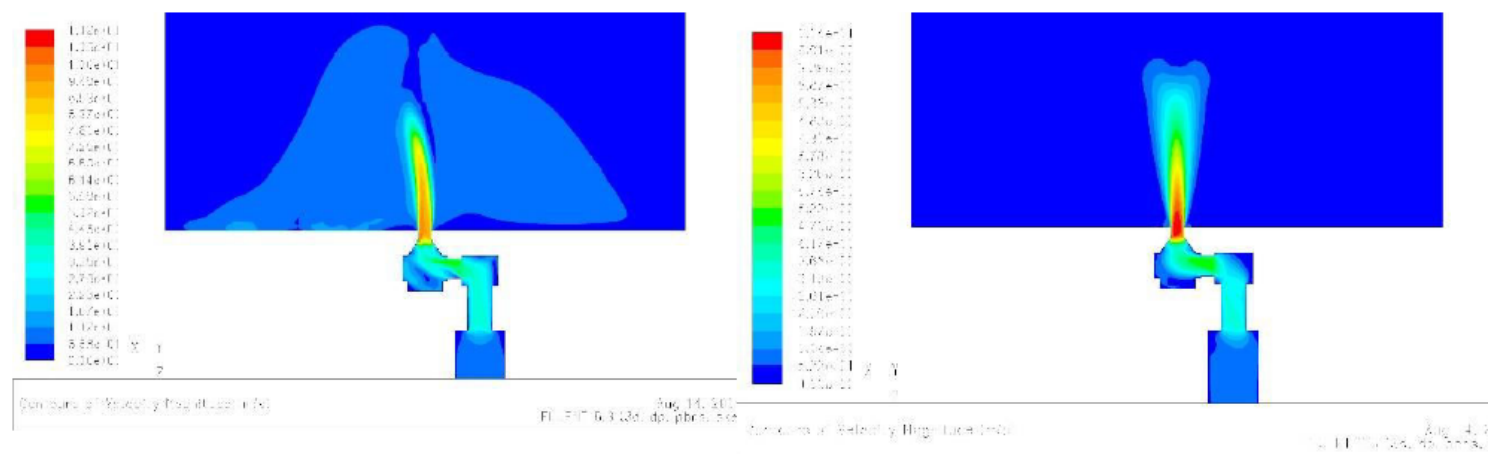

Figure 8. Contour speed at a viscosity of $8.5 \mathrm{cP}$ and $9.3 \mathrm{cP}$ and $\oslash$ tips $7 \mathrm{~mm}$

\section{Conclusions}

Based on analytical and numerical studies the failure of the gun nozzle can be caused by the clogging of the tip / tip of the nozzle. Clogging can occur at start up or uneven heating at the tip or tip nozzle. The presence of clogging from operations can detect a pressure increase.

With regard to clogging, additional sensors or temperature monitoring are needed to ensure the temperature of the tip nozzle matches the temperature of the liquid sulfur operation.

1. Prevention of nozzle damage by adding a pressure and pressure relief sensor to the liquid sulfur inlet so that it can detect clogging.

2. Modification of liquid sulfur duct pipes made individually, where each gun nozzle is one channel with a pressure gauge (manometer) per intake pipe.

\section{References}

[1] D. M. Himmelblau, "Basic principles and calculation in chemical engineering 5th edition," Prentice Hall International Inc, 1989.
[2] S. P. Max, D. T. Klaus, and E. W. Ronald, "Plant design and economics for chemical engineers," International edition, 1991.

[3] Y. Hardalupas, A. Taylor, and J. Whitelaw, "Characteristics of the spray from a diesel injector," International Journal of Multiphase Flow, vol. 18, no. 2, pp. 159179, 1992.

[4] C. S. Lee and S. W. Park, "An experimental and numerical study on fuel atomization characteristics of high-pressure diesel injection sprays," Fuel, vol. 81, no. 18, pp. 2417-2423, 2002.

[5] B. Sudarmanta, D. Sungkono, M. Rachimoellah, and S. Winardi, "Diesel and palm methyl ester fuel atomization characteristics of pintle type diesel injection spray," Jurnal Industri (Terakreditasi), Fakultas Teknologi Industri, ITS Surabaya, vol. 5, no. 3, 2006.

[6] A. Lefebvre, "Fuel atomization, droplet evaporation, and spray combustion," 1991. 